\title{
TESTING FOR ASYMMETRY IN THE LINK BETWEEN The Yield Spread and Output in the G-7 Countries
}

\author{
John W. Galbraith and Greg Tkacz* \\ Department of Economics Department of Monetary and Financial Analysis \\ McGill University Bank of Canada \\ 855 Sherbrooke St. W. 234 Wellington St. \\ Montreal, QC H3A 2T7 Ottawa, ON K1A 0G9 \\ Canada Canada
}

\begin{abstract}
The difference in yields between long-term and short-term securities has been used both as a business cycle leading indicator and as an indicator of the current impact of monetary policy. This paper tests for an asymmetry, in the form of a threshold effect, such that the impact of the yield spread on output is greater on one side of the threshold than the other. The test allows for an unknown threshold, and the asymptotic distribution of the resulting statistic is obtained by the method of Hansen (1996). We test using data from each of the G-7 countries, and find that, while the yield spread does generally show a significant link with output, only in the U.S. and Canada is there strong evidence of an asymmetry of this type. The evidence of asymmetry that we find suggests a high value of the threshold in both the U.S. and Canada.
\end{abstract}

JEL Classification number: E52

* This research was supported financially by the Quebec Fonds pour la Formation de chercheurs et l'aide à la recherche, the Social Sciences and Humanities Research Council of Canada (Galbraith) and the McGill Institute for the Study of Canada (Tkacz). The authors thank Jean-Pierre Aubry, Benoît Carmichael, Tiff Macklem, Simon van Norden and participants in the CREFE/Bank of Canada conference New Approaches in the Estimation of Monetary Policy Effects for valuable comments. Views expressed by Tkacz do not necessarily reflect those of the Bank of Canada. 


\section{Introduction}

There has been a good deal of recent interest in the link between yield spreads and aggregate economic activity, for several related reasons. First, the yield spread, specifically the difference in yields between long-term and short-term interest-bearing securities, has been found to be one of the most useful business cycle leading indicators; see, e.g. Estrella and Hardouvelis (1991), Bernanke and Blinder (1992), Cozier and Tkacz (1994), Lahiri and Wang (1996). Second, there is a popular argument (espoused by Laurent 1988, for example) to the effect that the interest rate spread acts as an indicator of the direction of monetary policy. To the extent that this is true, the value of the spread in serving as a leading indicator of aggregate activity could be the result of its value in summarizing the current impact of monetary policy, which affects aggregate output in the future.

A third important point is that the yield spread (or slope of the yield curve) is a variable that can be observed immediately, and with virtually no measurement error or approximation error arising from the use of an index, which distinguishes it from many other indicators and is one possible explanation for its empirical usefulness as a business cycle indicator.

The present paper examines this yield spread-output link, and in particular the possible existence of asymmetries in the relationship. The examination of asymmetries is suggested by, and in part derives its importance from, the frequently-reported finding of asymmetries in derived measures of current monetary policy or money supply changes, such as those of Cover (1992), Morgan (1993) and Karras (1996). At the same time, this paper uses data from the entire G-7 group of countries, rather than the U.S. alone. ${ }^{1}$

\footnotetext{
${ }^{1}$ Karras also pursues this strategy in examining asymmetries in derived measures of money supply shocks, but aggregates the data across a sample of European countries rather than
} 
Asymmetry, if present, implies that the information content of the spread cannot be fully exploited in a linear model. Less formally, the existence of asymmetry here, as in other contexts where policy can affect events, would imply that we should anticipate greater proportionate impacts for some values than for others; policy actions and forecasts should be adapted accordingly.

To test whether the yield spread has an asymmetric impact on output, we test for a threshold effect in the relation. We do so by treating as unknown the threshold beyond which the effect of the yield spread becomes greater (or smaller); evidence of a threshold effect is evidence in favour of asymmetry (or of some other non-linearity which can be approximated in this way). We use the test proposed by Hansen (1996), which allows testing for a threshold effect without a priori knowledge of the threshold value. Treating the threshold as unknown has the advantage that it allows us to consider the likelihood of asymmetry contingent upon a number of different threshold points, and also requires us to use a test which explicitly accounts for the fact that the choice of threshold is based on the likelihood. Earlier test procedures that implicitly or explicitly use threshold values that maximize the likelihood of finding asymmetry invalidate the nominal distributions used for inference; we will return to this point below. Moreover, by leading us to consider a set of possible thresholds, this method gives us a more general overview of the usefulness of the asymmetry hypothesis in describing the relation between yield spreads and output.

In examining the relationship in this way, we find a distinction between North American and non-North-American data. This suggests the possibility that the transmission mechanisms in different developed countries may be substantially different, and therefore that it might be fruitful to attempt to understand the reasons for apparent differences in examining individual country effects. 
the form (as well as the strength) of this mechanism across countries. We also offer a few conjectures about these differences.

The next section discusses in more detail the use of the yield spread, or slope of the yield curve, as a leading indicator, and as an indicator of monetary policy. Section 3 presents the data and models. The threshold tests are reported in Section 4, while Section 5 concludes.

\section{The yield spread as current and leading indicator}

Economists have been interested in business cycle indicators since at least the seminal work of Mitchell and Burns (1938). A good indicator is valuable to policy-makers primarily in helping to reduce the policy recognition lag, and is particularly important where aggregate output is concerned, given both the time required for initial GDP estimates to be released, and the fact that revisions to the initial estimates are often substantial.

A good indicator should be, among other things, timely and precisely measured. The yield spread meets both of these requirements very well, being available immediately, daily, and being virtually free of the measurement errors which plague many macroeconomic data series. Moreover, although the yield spread was not examined in the early NBER work on indicators, a number of recent studies have concluded that it is one of the better business cycle indicators available, and it has been successfully used to predict output growth in the U.S. and other countries. This is the finding of Stock and Watson (1989) and Estrella and Hardouvelis (1991) for the U.S., Cozier and Tkacz (1994) for Canada and Harvey (1991) for the G-7 countries. In most cases these authors find that the yield spread leads output growth by about eighteen months, and that it out-performs a number of competing indicators such as monetary aggregates and stock indexes. 
One hypothesis often suggested to explain the value of the yield spread as a leading indicator for aggregate output is that it may be serving as a current indicator of the direction of the effect of monetary policy on the aggregate economy. This is the view of, for example, Laurent (1988). The argument in favour of the hypothesis holds that the central bank exerts a considerable amount of control over short-term rates, but is only capable of influencing long-term rates insofar as it can influence inflation expectations. ${ }^{2}$ As a result, a tightening of monetary policy results in higher short-term rates, causing the gap between short and long rates to narrow. As mentioned above, authors such as Estrella and Hardouvelis (1991) find that the yield spread leads output growth by about eighteen months, which is consistent with the effectiveness lag of monetary policy implied by the interest rate channel of the monetary policy transmission mechanism. Blinder (1996), for example, notes that the time lapse occurring between a monetary policy action and changes to actual output is roughly in the range of one and a half to two years.

The yield spread has advantages over the use of changes in a short rate alone, since the effects of external shocks can be dampened, leading to a better indicator of deliberate policy actions. For example, the oil shocks of 1973 and 1979 affected the yields of U.S. securities at all maturities, represented by an upward shift of the entire yield curve. Although the spreads between long and short rates widened, the effects of the shocks on the spread were mild relative to changes in the federal funds rate alone. If therefore the monetary authority has significant influence in the determination of short-term rates through the control of bank reserves, and little control over long-term rates, then the spread should be a good indicator of policy; the collection of papers by the central bankers of several

\footnotetext{
${ }^{2}$ For recent empirical evidence on the Fed's weak control of long rates, see Mehra (1996); Akhtar (1995) offers a comprehensive survey of the literature.
} 
industrial countries in BIS (1995) suggests that such a pattern of control over interest rates does indeed hold for most of the G-7 countries. A notable exception is Japan where, as Tatewaki (1991) notes, financial markets were heavily regulated until the early 1980's; as a consequence some interest rates, such as those on long-term government bonds, did not adequately reflect marked conditions. Only after banks were allowed to engage in the dealing of long-term bonds in 1984 did the secondary market expand rapidly. Thus we may expect the yield spread to be a poor indicator of Japanese monetary policy before about 1984. With this possible exception, another desirable feature of the spread is the ease with which comparable indicators of monetary policy can be constructed across countries.

For all of these reasons, the spread is a useful and interesting indicator. We now consider whether, in parallel with the literatures involving other measured aspects of the monetary transmission process, we can detect asymmetry in the effects of this variable. We also consider threshold tests on the short-term interest rate, for comparison. To the extent that there is such evidence, we look for the diminished effectiveness at strongly expansionary values which has been detected in measures of money supply shocks, particularly in the U.S.

\section{Data and models}

For each country we assemble a data set containing time series of real output (gross domestic product), real government expenditure, short- and long-term interest rates. Precise variable definitions and data sources are described in the Appendix. All series except interest rates are transformed to logarithms. In order to construct a consistent German data series, we use data applying to the pre-unification borders of West Germany through 1994, the last year for which we could obtain data reported on this basis. 
The yield spread is simply the difference between the long- and short-term interest rates at any point in time. However, because GDP data are only available at quarterly frequency, we must construct a quarterly spread variable from higher-frequency interest rate data. As well, GDP measurements reflect developments over the entire quarter rather than purely at a point in time; we therefore use a quarterly average for the spread rather than a point-in-time value. To capture dynamics in the effect of the spread, we also consider several moving averages of the quarterly spread in defining the monetary indicator, $\omega_{t}$, used in the tests below. The current quarterly-average spread is defined to be the mean of the present month's spread and two monthly lags; the previous quarter's spread is the mean of the monthly spreads in months three to five preceding the last month of the current quarter, and so on.

The tests used in Section 4 require stationary regressors. For each of the seven countries, therefore, we begin by specifying a model of the changes in the logarithm of real output. The models are derived from the general form

$$
\Delta y_{t}=\alpha_{0}+\sum_{i=1}^{p} \alpha_{i} \Delta y_{t-i}+\sum_{i=0}^{k} \gamma_{i} \Delta g_{t-i}+\sum_{i=1}^{\ell} \delta_{i} \omega_{t-i}+\epsilon_{t}
$$

where $y_{t}$ is the logarithm of real GDP, $g_{t}$ is the logarithm of real government expenditure, and $\omega_{t-i}$ is a function of the spread to be defined below. Some of the models also incorporate a change in the short-term interest rate in addition to, or in place of, $\omega$. 
Table 1: Estimation results for models without threshold ${ }^{3}$

Model (1) with three-quarter moving-average definition of the spread ${ }^{4}$

\begin{tabular}{|c|c|c|c|c|c|c|c|}
\hline $\begin{array}{l}\text { Coef. or } \\
\text { statistic }\end{array}$ & $\mathrm{Ca}$ & $\mathrm{Fr}$ & $W G$ & $I$ & $J$ & $U K$ & $U S A$ \\
\hline constant & .006 & .005 & .005 & .004 & .003 & .003 & .004 \\
\hline$(t-)$ & 5.90 & 3.08 & 2.81 & 3.24 & 1.53 & 1.87 & 3.97 \\
\hline$\Delta y_{t-1}$ & 0.12 & -0.30 & -0.12 & 0.40 & -0.09 & -0.09 & 0.18 \\
\hline$(t-)$ & 1.64 & -3.75 & -1.49 & 4.11 & -1.08 & -1.23 & 2.46 \\
\hline$\Delta y_{t-2}$ & - & - & - & 0.17 & 0.22 & - & - \\
\hline$(t-)$ & - & & & 1.83 & 2.76 & & \\
\hline$\Delta y_{t-3}$ & - & - & - & -0.24 & 0.18 & - & - \\
\hline$(t-)$ & & & & -2.86 & 2.13 & & \\
\hline$\Delta g_{t}$ & 0.06 & 0.31 & 0.31 & 0.20 & 0.23 & 0.27 & 0.20 \\
\hline$(t-)$ & 2.91 & 4.44 & 4.13 & 4.82 & 4.76 & 5.15 & 3.26 \\
\hline$\Delta g_{t-1}$ & - & - & - & -0.08 & - & - & - \\
\hline$(t-)$ & & & & -1.71 & & & \\
\hline$\omega_{t-1}\left(\times 10^{3}\right)$ & 2.65 & 1.87 & 2.46 & 1.04 & 0.90 & 1.56 & 1.85 \\
\hline$(t-)$ & 5.26 & 1.91 & 2.95 & 1.92 & 0.83 & 2.18 & 4.49 \\
\hline Obs. & 162 & 128 & 136 & 104 & 121 & 144 & 170 \\
\hline d.f. & 158 & 124 & 132 & 97 & 115 & 140 & 166 \\
\hline$R^{2}$ & 0.23 & 0.26 & 0.18 & 0.43 & 0.27 & 0.21 & 0.23 \\
\hline$z_{B S}$ & 1.42 & 358 & 19.8 & 5.06 & 11.6 & 28.0 & 7.22 \\
\hline$z_{a}$ & 5.94 & 4.04 & 19.4 & 2.67 & 8.92 & 5.84 & 3.83 \\
\hline$z_{h}$ & 4.57 & 35.0 & 8.39 & 15.4 & 31.7 & 1.22 & 10.5 \\
\hline$r$ (d.f.) & 6 & 6 & 6 & 12 & 10 & 6 & 6 \\
\hline
\end{tabular}

${ }^{3}$ The statistics $z_{B S}, z_{a}$ and $z_{h}$ are respectively the Bowman-Shenton test for residual normality, an LM autocorrelation test on lags 1-4, and an LM heteroskedasticity test. Their asymptotic distributions are $\chi_{2}^{2}, \chi_{4}^{2}$ and $\chi_{r}^{2}$ respectively, where $r$ is given in the table. The number of observations is that which remains after allowing for lagged values. ${ }^{4}$ This corresponds to the Case B definition of section 4. 
Table 1 summarizes the results of fitting model (1) for each of the seven countries. These models reflect separate specification searches to select lag lengths for each country, and a base-case definition of $\omega_{t-1}$ as a three-quarter moving average of the quarterly spread defined above. The dating of this variable at $t-1$ reflects the fact that the current-quarter spread is not incorporated into any definition of the spread variable used below, consistent with its possible use as a leading indicator.

These estimated representations are the context within which testing for a threshold effect will take place. The tests require that we define an additional threshold effect, that is, $\widetilde{\omega}_{t-1}=\omega_{t-1} I\left[\omega_{t-1} \leq \tau\right]$, where $\tau$ is the threshold parameter and where the indicator function is

$$
I\left[\omega_{t-1} \leq \tau\right]= \begin{cases}0, & \text { for } \omega_{t-1}>\tau \\ 1, & \text { for } \omega_{t-1} \leq \tau\end{cases}
$$

Models based on (1) will then be estimated which include as regressors not only the original spread variable $\omega_{t-1}$ but also the threshold variable $\widetilde{\omega}_{t-1}$, with a coefficient that we will call $\eta$. If the yield spread variable has a linear effect on output, then $\eta=0$. Again, analogous tests will also be carried out on the change in the short rate, for comparison.

\section{Tests for asymmetry around an unknown threshold}

\subsection{Test procedure}

The aim of this section is to carry out tests for asymmetry, or statistical significance of the threshold variable $\widetilde{\omega}_{t-1}$, without specifying a priori the value of the threshold. Doing so offers two potential advantages. First, the process of searching across a set of threshold values offers the best chance of finding any threshold effect which does exist: we can compute the point around which any asymmetry is maximized. Most existing tests take zero as the threshold; it is possible, however, that a distinction will be more readily 
apparent between values above and below some other point. Of course, such a procedure invalidates standard inference.

Fortunately, there are tests whose distributions can be computed given a threshold value chosen, in effect, to maximize the likelihood function of the model. Standard tests, by contrast, treat the value of the threshold parameter as known. It is of course true that a standard test (e.g., a $t$-test) of the null of symmetry, treating the value of the threshold parameter as known, is valid when that value is selected independently of the data. However, one might doubt that such independent selections could be made in data sets as widely explored as those involving output and monetary variables in major industrial countries. A second advantage of the type of test used here is that, by allowing explicitly for maximization of the likelihood over the threshold parameter, we deal with the implied potential for pre-test bias. This problem can imply a large departure from the nominal distribution; see Galbraith (1996) for a simulation example.

The test procedure that we use, which explicitly accounts for the fact that the threshold parameter is not identified under the null hypothesis, is that of Hansen (1996). Hansen's procedure allows us to simulate the limiting distribution of supremum statistics which emerge from maximization over the values of the threshold parameter. From the simulation results, the asymptotic distribution can be estimated, and p-values obtained. Simulations in Hansen (1996) suggest good size and power performance of the tests based on either the supremum or the average of LM and Wald statistics. Here we report the maximum of the sequence of LM statistics. The threshold parameter is allowed to take, in turn, each value in the sample range of the spread variable; following Andrews (1993), this set of values is then trimmed by $15 \%$ of the sample at each end before computing the sup(LM) statistic. The p-values from the asymptotic distributions are then obtained from 1000 replications 
of the simulation procedure.

As in any test based on a regression model, the results will depend to some extent on the specification of that model, the purpose of which is to control adequately for effects other than those of the variable of interest. In order to examine the robustness of results to small changes in the model, we consider a set of possible specifications and associated test statistics, in the next sub-section.

\subsection{Model specification and sensitivity analysis}

Table 2 gives asymptotic p-values, corresponding to the null of no threshold effect, for each of the seven countries and for four possible specifications of the threshold variable, and four other model specifications. Using the model type given in (1) above, Cases A through $\mathrm{C}$ correspond to the specification

$$
\omega_{t-1}=\left(\frac{1}{q}\right) \sum_{i=1}^{q} s_{t-i}
$$

where $q=2,3,4$ respectively. Case $\mathrm{D}$ does not use an average of this type, but instead takes a single quarterly lag of the spread, defining $\omega_{t-i}=s_{t-i}$. The particular lag is chosen to maximize the likelihood function. The estimated models described in Table 1 embody the Case B definition, and apart from the varying definition of $\omega_{t-1}$, the results in Cases A-D of Table 2 results all use the models given in Table 1 . In performing this sensitivity analysis with respect to functions of the spread, our aim is to conserve test power by concentrating the predictive content in a single variable, and also to avoid dependence on a particular weighting of lagged spreads in computing test statistics.

Table 2 also explores sensitivity to specification of the test regression. In the second block of the table, the Case B specification of the spread variable is used in the following sets of models: Case E, a model in which all terms in $g$ are omitted, leaving only dynamics 
in the dependent variable and the spread variable; Case F, like the base case B but with a lagged difference of the short-term interest rate added; Case G, like the simpler model of Case $\mathrm{E}$ but with the lagged difference of the short-term interest rate added; and Case $\mathrm{H}$, in which the spread variable in the base case is omitted and replaced with the short-rate variable (in contrast with Case $\mathrm{F}$, in which the two interest-rate variables appear). In this last case, the threshold test is applied to the short-rate variable instead of to the spread; in cases $\mathrm{F}$ and $\mathrm{G}$, the test is applied to both interest rate variables. Results pertaining to the short rate rather than to the spread are shown separately in the third block of Table 2.

Table 2: p-values for the null of no asymmetric effect ${ }^{5}$

$\begin{array}{llllllll}\text { Case } & \text { Ca } & \text { Fr } & W G & I & J & \text { UK } & \text { USA }\end{array}$

(i) Sensitivity to definition of the spread variable

$\begin{array}{llllllll}\mathrm{A} & .03 & .25 & .53 & .15 & .97 & .18 & .09 \\ \mathrm{~B} & .01 & .41 & .31 & .16 & .79 & .17 & .03 \\ \mathrm{C} & .01 & .52 & .31 & .29 & .31 & .09 & .02 \\ \mathrm{D} & .01 & .46 & .32 & .24 & .16 & .13 & .02\end{array}$

(ii) Sensitivity to specification of the test regression

$\begin{array}{llllllll}\mathrm{E} & .02 & .11 & .41 & .43 & .95 & .30 & .02 \\ \mathrm{~F} & .01 & .41 & .29 & .16 & .73 & .16 & .04 \\ \mathrm{G} & .01 & .11 & .40 & .43 & .97 & .25 & .03\end{array}$

(iii) Tests pertaining to the short-rate variable

$\begin{array}{llllllll}\mathrm{F} \text { (spread) } & .13 & .94 & .43 & .12 & .12 & .74 & .10 \\ \mathrm{G} \text { (spread) } & .14 & .77 & .33 & .12 & .01 & .85 & .11 \\ \mathrm{H} & .03 & .05 & .27 & .50 & .07 & .89 & .01\end{array}$

${ }^{5}$ Estimated p-values less than 0.01 are shown as 0.01 : the one thousand replications of the test simulations used here are insufficient to distinguish very small values. 
There are several noteworthy points. First, at the conventional level of 0.05 or $5 \%$, there is no statistically significant evidence of threshold effects of the spread outside the U.S. and Canada; by contrast, the null of no asymmetry is soundly rejected in both of those countries. However, it is important that, from Table 1, the U.S. and Canada are the two countries for which the effect of the spread variable itself was most strongly significant; the yield spread tended to be near the borderline of conventional significance in four of the other five countries. In the Japanese case, the yield spread was statistically insignificant. Our inability to detect a departure from the linear effect may be attributable to the weakness or absence of the effect of the yield spread in some of these countries, particularly Japan; recall the argument of Tatewaki (1991) described above.

There is little dependence of these qualitative results on the specification of the spread variable or on the model specification. While some variation in the p-values does occur across models, qualitative results are virtually insensitive to these specification choices.

With respect to tests on the change in the short-term rate in Case $\mathrm{H}$, and as additional regressor in Cases F and $\mathrm{G}$, the results are generally weaker in the U.S. and Canada, an outcome compatible with findings cited above suggesting that the spread is the superior indicator. In Japan, by contrast, results are much stronger: one 1\%-level rejection appears, and the other two p-values are near $10 \%$. Such an outcome is consistent with the superior performance of the short-term rate alone for Japan as an indicator of monetary policy, because of the unreliability of long-rate measures, as discussed above. In other countries there is, again, little evidence against the null of no asymmetry.

The result suggesting asymmetry in the U.S. is consistent with a good deal of previous literature concerning the impacts of money supply shocks in the U.S., although the procedure here offers the advantage of providing a test valid with data-based selection of the 
point around which asymmetry is observed. In the U.S., the evidence points to asymmetry around a large positive value of the spread (around 195 basis points or 1.95 percentage points in the base case), but not around values near zero. That is, the linearity of the effect of the yield spread on output, or on appropriate forecasts of output, appears to break down for large (strongly expansionary) values of the spread. This is also consistent with the results on U.S. data from similar inferential procedures in Galbraith (1996), where money supply measures were used in examining credit rationing models. In Canadian data as well, the optimal value of the threshold is estimated to be a large positive number (1.44 percentage points in the base case). ${ }^{6}$

As a further aid to interpretation of these results, consider Figures 1 and 2 which depict the asymmetric relationships between the yield spread and output growth for Canada and the U.S. respectively. These curves are constructed by subtracting the non-spread effects from the fitted output growth values in the Case B model specification, using the optimized value of the threshold. Note that the test procedure adopted above does not force the lines above and below the threshold to meet at a single point; hence the discontinuity at the threshold.

Again, we find that these optimized values of the threshold lie at large positive values for both Canada and the U.S. for both countries. If we accept that the yield spread captures the direction of monetary policy in some degree, then such values for the threshold would be associated with strongly expansionary monetary episodes, since short term rates are far below long-term rates. When the significant threshold terms $\widetilde{\omega}_{t-1}$ based on these values are incorporated into the models, we can compare estimates of the augmented models ${ }^{6}$ In Cases A-D of Table 2, the estimated threshold values for the U.S. are 2.07, 1.95, 1.91 and 2.14 percentage points respectively; for Canada, 1.82, 1.44, 1.48 and 2.13 percentage points. 
with estimates of the base-case models presented in Table 1 . The augmented model of the Canadian data is estimated as

$$
\Delta y_{t}=0.007+0.10 \Delta y_{t-1}+0.06 \Delta g_{t}+1.22 \times 10^{-3} \omega_{t-1}+3.46 \times 10^{-3} \widetilde{\omega}_{t-1} ;
$$

the augmented model of the U.S. data is estimated as

$$
\Delta y_{t}=0.004+0.16 \Delta y_{t-1}+0.19 \Delta g_{t}+0.70 \times 10^{-3} \omega_{t-1}+1.96 \times 10^{-3} \widetilde{\omega}_{t-1} .
$$

These results can be interpreted as follows. To the extent that the yield spread captures the impact of monetary policy on output growth, then this impact is substantial and statistically significant. However, the additional impact obtained from a very large spread is small and of dubious statistical significance: the below-threshold terms $\widetilde{\omega}_{t-1}$ are strongly significant, but the additional effect proportional to spread with no threshold $\left(\omega_{t-1}\right)$ is not statistically significant in the U.S., and is borderline in Canada (at conventional levels).

If the spread is simply viewed as a leading indicator, a higher spread always suggests higher output growth, but the proportionate impact of the spread is reduced for large spread values; additional declines in short-term rates relative to long-term rates have diminished marginal impacts once the threshold level is crossed. To the extent that the link is viewed as causal because the spread represents monetary policy, the effect of strongly expansionary yield spreads is proportionately lower than that of more moderate values, but the marginal impact of more aggressively expansionary policy is nonetheless always positive. $^{7}$

\footnotetext{
${ }^{7}$ In making this interpretation we of course ignore the discontinuity that appears in the unconstrained estimates of Figures 1 and 2.
} 


\section{Concluding remarks}

The use of some transformation of the spread between long-term and short-term interest rates is successful in predicting changes in output in all G-7 countries except Japan. Other evidence has also suggested that such information generally provides a good measure of the direction of monetary policy. However, using this indicator on G-7 data produces little evidence of asymmetric effects of the yield spread outside the U.S. and Canada.

One legitimate interpretation of these results is that the non-rejections in most countries of the sample simply reflect lower test power, possibly because the spread is itself a weaker indicator of the impact of monetary policy than in the North American economies, leading to a reduced ability to detect relatively subtle features of the relationship. On this interpretation, threshold asymmetry or other non-linearity will eventually be reliably detectable as further sample information accumulates.

The other possibility is that there are genuine differences in the monet ary transmission mechanisms of the G-7 countries with respect to the importance of a non-linearity of this type. If this is so, it is interesting to ask why the U.S. and Canada appear to differ from other countries. It may be that any difference lies in some uniqueness of the U.S., while the similarity of Canadian results follows from the importance of U.S. monetary policy in constraining Canadian monetary policy; the very strong trade and investment links between the two economies, and the sensitivity of Canada-US capital flows to the interest rate differential, make this suggestion plausible. An explanation for the U.S. result might lie in the world-currency role of the U.S. dollar, ${ }^{8}$ and in the relatively low degree of dependence on foreign trade of the U.S. economy. In many countries, monetary policy operates through both interest rate and exchange rate channels; expansionary policy that ${ }^{8}$ We thank J.-P. Aubry for suggesting this explanation. 
lowers interest rates also tends to cause a depreciation of the domestic currency, thereby expanding domestic output. In the U.S., because of both the relatively low importance of trade, and the fact that many commodities are priced in U.S. dollars, the exchange rate channel might assume less importance. It is possible that outside the U.S., exchange-rate effects can mitigate a diminished effectiveness of monetary policy through the interest-rate channel when spreads become very high (policy attempts to be very expansionary); we may conjecture that this exchange-rate mechanism is of little importance in the U.S., so that the diminished effectiveness at high spreads does appear through a threshold effect.

We conclude that the evidence for asymmetry of effect of yield spreads on predicted output is strong in the U.S. and Canada, and weak outside, and that further research is necessary in order to understand the reasons for such differences as do exist. 


\section{References}

Akhtar, M.A. (1995) "Monetary Policy and Long-Term Interest Rates: A Survey of Empirical Literature." Contemporary Economic Policy XIII, 110-130.

Andrews, D.W.K. (1993) "Tests for parameter instability and structural change with unknown change point". Econometrica 61, 821-856.

Bank for International Settlements (BIS) (1995) Financial Structure and the Monetary Policy Transmission Mechanism. Basle: Bank for International Settlements.

Bernanke, B. and A. Blinder (1992) "The Federal Funds Rate and the Channels of Monetary Transmission." American Economic Review 82, 901-921.

Blinder, A. (1996) "Central Banking in a Democracy." Federal Reserve Bank of Richmond Economic Quarterly 82, 1-14.

Cover, J. (1992) "Asymmetric Effects of Positive and Negative Money-Supply Shocks." Quarterly Journal of Economics 107, 1260-1282.

Cozier, B. and G. Tkacz (1994) "The Term Structure and Real Activity in Canada." Working Paper 94-3, Bank of Canada, Ottawa.

Estrella, A. and G. Hardouvelis (1991) "The Term Structure as a Predictor of Real Economic Activity." Journal of Finance 46, 555-576.

Galbraith, J.W. (1996) "Credit Rationing and Threshold Effects in the Relation Between Money and Output." Journal of Applied Econometrics 11, 419-429.

Hansen, B.E. (1996) "Inference When a Nuisance Parameter Is Not Identified under the Null Hypothesis." Econometrica 64, 413-430.

Harvey, C.R. (1991) “The Term Structure and World Economic Growth.” Journal of Fixed Income 1, 7-19.

Karras, G. (1996) “Are the output effects of monetary policy asymmetric? Evidence from a sample of European countries." Oxford Bulletin of Economics and Statistics 58, 
$267-278$.

Lahiri, K. and J.G. Wang (1996) "Interest Rate Spreads as Predictors of Business Cycles." In G.S. Maddala and C.R. Rao, eds. Handbook of Statistics 14, 297-315.

Laurent, R.D. (1988) "An Interest-Based Indicator of Monetary Policy." Federal Reserve Bank of Chicago Economic Perspectives, 3-14.

Laurent, R.D. (1989) “Testing the 'Spread'." Federal Reserve Bank of Chicago Economic Perspectives, July/August, 22-34.

Mehra, Y.P. (1996) "Monetary Policy and Long-Term Interest Rates." Federal Reserve Bank of Richmond Economic Quarterly 82, 27-49.

Mitchell, W.C. and A.F. Burns (1938). "Statistical Indicators of Cyclical Revivals." In Business Cycle Indicators, Vol.1, G.H. Moore (Ed.) Princeton: Princeton University Press (1961):162-183.

Morgan, D.P. (1993) “Asymmetric Effects of Monetary Policy." Federal Reserve Bank of Kansas City Economic Review 78, 21-33.

Stock, J.H. and M.W. Watson (1989) "New Indexes of Leading and Coincident Economic Indicators." In O. Blanchard and S. Fischer, eds. NBER Macroeconomics Annual, $351-394$.

Tatewaki, K. (1991) Banking and Finance in Japan: An Introduction to the Tokyo Market. London: Routledge. 


\section{Appendix: data sources}

The definitions of the variables used in the paper are given below. All variables, with the exception of interest rates, are transformed to natural logarithms. National accounts and price data are seasonally adjusted. All data used are quarterly; interest rates and consumer prices were converted to quarterly observations by averaging the monthly observations within each quarter. Data were obtained from the International Monetary Fund's International Financial Statistics, the OECD's Main Economic Indicators, the FRED database at the Federal Reserve Bank of St. Louis, Statistics Canada's CANSIM database and the Bank of Canada.

1. Canada (1956:1 to $1997: 2)$

- Short-term interest rate: 90-day commercial paper rate (CANSIM B14017)

- Long-term interest rate: Average yield of 10-year and over Government of Canada marketable bonds (CANSIM B14013)

- Output: Nominal GDP (CANSIM D20000)

- Price level: GDP deflator, 1986=100 (CANSIM D20556)

- Government spending: Nominal government consumption and investment (CANSIM D20181 + D20192)

2. France (1965:1 to 1997:4)

- Short-term interest rate: Monthly average of rates for day-to-day loans against private bills (IMF 132F60BZ)

- Long-term interest rate: Average yield to redemption of public sector bonds with an original maturity of more than five years (IMF 132F61Z)

- Output: Nominal GDP (IMF 132F99CBZ)

- Price level: Consumer prices, 1990-100 (IMF 132F64Z)

- Government spending: Nominal government consumption (IMF 132F91CFZ)

3. (West) Germany (1960:1 to 1994:4)

- Short-term interest rate: Monthly average of ten daily average quotations for day-today money (IMF 134F60BZ)

- Long-term interest rate: Weighted average of all public sector bonds with an average remaining life to maturity of more than three years, or four years before January 1977 (IMF 134F61Z)

- Output: Nominal GNP (Bank of Canada)

- Price level: Consumer prices, 1991=100 (Bank of Canada)

- Government spending: Nominal government consumption (Bank of Canada)

4. Italy (1971:1 to $1997: 4)$

- Short-term interest rate: Three-month interbank rate (IMF 136F60BZ)

- Long-term interest rate: Average government bond yield, 9-10 years ( 15 -20 years prior to April 1991) (IMF 136F61Z) 
- Output: Nominal GDP (IMF 136F99CBZ)

- Price level: Consumer prices, 1990=100 (IMF 136F64Z)

- Government spending: Nominal government consumption (IMF 136F91CFZ)

5. Japan (1966:3 to 1997:4)

- Short-term interest rate: Lending rate for collateral and overnight loans in the Tokyo Call Money Market; prior to November 1990, lending rate for collateral and unconditional loans (IMF 158F60BZ)

- Long-term interest rate: 10 -year central government bond rate (OECD S0050562000AH)

- Output: Nominal GDP (OECD S005000100002)

- Price level: GDP deflator, 1990=100 (OECD S10500043009J)

- Government spending: Nominal government expenditures (OECD S105001200012)

6. United Kingdom (1961:1 to 1997:4)

- Short-term interest rate: 3-month Treasury Bill rate (IMF 112F60BZ)

- Long-term interest rate: Theoretical gross redemption bond yields. Issue at par with 20 years to maturity (IMF 112F61Z)

- Output: Nominal GDP (OECD S128000300002)

- Price level: GDP deflator, 1990=100 (OECD S12800043009J)

- Government spending: Nominal government consumption (OECD S128001210072)

7. United States (1954:3 to 1997:4)

- Short-term interest rate: Federal Funds Rate (Federal Reserve Bank of St. Louis)

- Long-term interest rate: 10-year government bond rate (Federal Reserve Bank of St. Louis)

- Output: Nominal GDP (Bank of Canada)

- Price level: GDP deflator, 1987=100 (Bank of Canada)

- Government spending: Nominal government consumption and gross investment (Bank of Canada) 